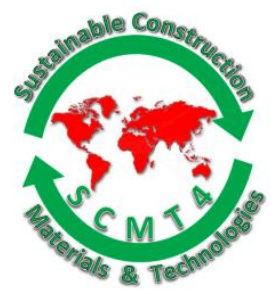

SCMT4

Las Vegas, USA, August 7-11, 2016

\title{
Compressive Strength and Leaching Behavior of Mortars with Biomass Ash
}

\author{
Gabriele Fava $^{1 *}$, Tarun R. Naik ${ }^{2}$. \\ ${ }^{I}$ Department of Materials, Environmental Science,s and Urban Planning (SIMAU). Università \\ Politecnica delle Marche. Ancona, ITALY; Email: *<g.fava@univpm.it>and <g.moriconi@univpm. \\ it>. \\ ${ }^{2}$ Emeritus Professor, Formerly Research Professor and Academic Program Director, UWM Center \\ for By-Products Utilization, University of Wisconsin-Milwaukee, P. O. Box 784, Milwaukee, WI, USA. \\ Tel:+414-395-6191;Email: 〈tarun@uwm.edu>.
}

\begin{abstract}
This study investigated the use of a biomass ash produced by a fuel combination made with wood, corn stover, and cob (WCSA) as cement replacement for mortars production. Biomasses are now well accepted to be able to substitute part of conventional fuels and are becoming essential for a costeffective production of energy. This study was aimed to provide an opportunity for the annual agricultural corn-crop residue, corn stover and cob, which is increasingly being used as fuel, for its valuable energy content. Measurements of workability, compressive strength, and leachate properties $(\mathrm{pH}$, salinity, heavy metals and Calcium ion release) of mortars specimen, at different cement substitution levels and ages, were evaluated. The results obtained reveal definitive possibilities for such mixed biomass ash to be used in cement-based materials, such as mortars. Data show that further confirmation, on a longer span of time and of other types of mechanical properties and environmental tests, would be necessary to fully implement the use of such bio-mass ashes in various types of cementbased construction materials.
\end{abstract}

\section{INTRODUCTION}

The use of renewable raw materials is continuing to increase. Certain biofuels resources, such as wood, are becoming scarce in some regions [Kaltschmitt et al.2008]. In addition, wood is not available in every areas of every country, depending on its climatic and soil conditions. With the increased price of fossil fuels, as well as decreased desirability for the use of such fuels, annual agricultural crops, such as straw or whole cereal plants are reaching closer to economic profitability [Thrän, 2006]. However, there are many reasons for the presently low use of agricultural crops residues for combustion. Compared to wood, herbaceous plants show some unfavorable fuel properties. Fuel type and its characteristics affect the combustion process either in a technical or an ecological way. Technical problems can, for example, be due to the presence of chlorine, sulphur, potassium, nitrogen, magnesium, and/or calcium that can cause corrosion, and even slagging problems in the combustion boiler-plant and consequentially reduce the useful life of the combustion equipment. Other chemical components, such as heavy metals in the ash can result in excessive pollutant emissions or remain in the ash, leading to challenges in the disposal (Table 1).

Ash, therefore, should undergo a broad and critical assessment before being disposed, with the aim to provide an option for beneficial use in construction materials. The assessment should include the evaluation of reducing the cost of construction materials, as well as helping in reducing disposal 
costs, accounting for long-term and short-term challenges. Leaching characteristics are essential in understanding the environmental impact or toxicity, disposal issues, and potential development of beneficial use applications of the WCSA. This study presents micro-structural \& mechanical behavior, and metal analysis of leachate obtained from mortars made with various percentages of WCSA $(0 \%, 10 \%, 20$ and $30 \%)$.

WWCSA was collected from a conventional-boiler after combustion of biomass (wood, corn stover, corn cob, and landfill gas) at about $1000 \mathrm{deg}$. C.

Table 1. Heavy metal contents of WCSA compared to the published heavy metal data of coniferous wood and crop of grain straw

\begin{tabular}{|c|c|c|c|}
\hline \multirow{2}{*}{ Element } & Data for Corn Plant & \multicolumn{2}{|c|}{$\begin{array}{c}\text { Published data for comparison } \\
\text { (Hartmann et al. 2000) }\end{array}$} \\
\hline Chrome & $\begin{array}{c}\text { Corn, wholeplant } \\
{[\mathrm{mg} / \mathrm{kg} \text { d.b. }]}\end{array}$ & $\begin{array}{c}\text { coniferous wood }[\mathrm{mg} / \mathrm{kg} \\
\text { d.b. }]\end{array}$ & $\begin{array}{c}\text { grain straw } \\
{[\mathrm{mg} / \mathrm{kg} \text { d.b. }]}\end{array}$ \\
\hline Cobalt & 4,85 & 4,50 & 4,62 \\
\hline Copper & 0,23 & 0,35 & 0,14 \\
\hline Manganese & 6,08 & 3,45 & 2,21 \\
\hline Molybdenum & 46,25 & 344,70 & 22,00 \\
\hline Nickel & 2,53 & 1,12 & 0,38 \\
\hline Zinc & 0,62 & 4,23 & 0,69 \\
\hline
\end{tabular}

Fly ash from biomass co-firing with coal have already been used as a component of ordinary portland cement (OPC) for producing cement-based construction materials; however, limited research has been reported on the biomass ash alone [Maciejewska, et al., 2006, Bakisgan C. et al.2009; Dwivedi V, et al. 2006; Elinwa,and Mahmood 2002, Berra et al. 2009; Naik and Kraus,2003; Naik .et al. 2001]. The hydration behavior of OPC in the presence of biomass ash needs to be assessed as a suitable material for mechanical properties and environmental impact [Dwivedi V et al. 2006; Dwivedi V, et al. 2006; Naik and Kraus,2003; Naik et al. 2001]. An Italian law protocol, designed to assess the environmental impact for a biomass ash reuse, is based on a leaching test to be performed, both on the ash as such or in the form of its reuse (such as in concrete), in the range of $\mathrm{pH}$ of the leaching, which is presumed to be actual field work of the form recovered in different environmental exposure conditions [Naik et a. 2001]. In the present research, this leaching protocol was applied to the cement-based specimens, mortar cubes, containing WCSA as supplementary cementitious material that was used as a binder replacement for the use in concrete production. The effects of the ash content were evaluated through comparison of: (i) compressive strength as a function of time; (ii) ions leaching release as a function of time; and, (iii) as a relationship between compressive strength and leaching.

Materials. The average ash content in maize plants shows a relatively low value, more or less within a range between 2.1 and $2.7 \%$ [Kaltschmitt et al.2008]. Ash contents are generally inversely correlated with the calorific value, which for a corn stalk is reported around $7 \%$ lower than wood, ranging from 16.7 to $18.0 \mathrm{MJ} / \mathrm{kg}$ for the whole plant. Similar to the ash content, the chemical parameters nitrogen, potassium, and chlorine largely remain constant compared to wood. While the contents of nitrogen are relatively high in comparison to wood or wheat straw, potassium is in between wood and straw and chlorine is low. 
The light-gray colored WWCSA used for this research has a specific gravity of $1.90 \mathrm{~g} / \mathrm{cm}^{3}$. The main oxides content of WCSA as analyzed by EDXA is reported on Table 2 and figure 1 . The mineralogical characterization for WCSA was determined by X-ray diffraction (XRD) spectroscopy is reported in figure 2. Due to their relevance in understanding the hardening performance of WWCSA morphological properties were obtained by SEM-EDS Analysis (figure 3 and 4). The analysis revealed that the inorganic portion of the ash sample consisted predominantly of porous irregular particles, mainly Potassium, Sodium, and Calcium with fractions of Sulfur and Chlorine. X-ray diffraction analysis showed the presence of Quartz (SiO2), Calcite (CaCO3), Arcanite (Potassium Sulphate), Sylvite (Calcium Chloride), and Anhydride (Calcium Sulphate).

Table 2. Main Oxides Composition from EDXA Analysis of WCSA

\begin{tabular}{|c|c|c|c|c|c|c|c|c|c|c|}
\hline Units & $\mathrm{Na}$ & $\mathrm{Mg}$ & $\mathrm{Al}$ & $\mathrm{Si}$ & $\mathrm{P}$ & $\mathrm{S}$ & $\mathrm{Cl}$ & $\mathrm{K}$ & $\mathrm{Ca}$ & $\mathrm{Fe}$ \\
\hline$\%$ & 5,62 & 3,96 & 8,20 & 39,94 & 3,31 & 6,03 & 2,63 & 7,09 & 16,52 & 5,02 \\
\hline
\end{tabular}

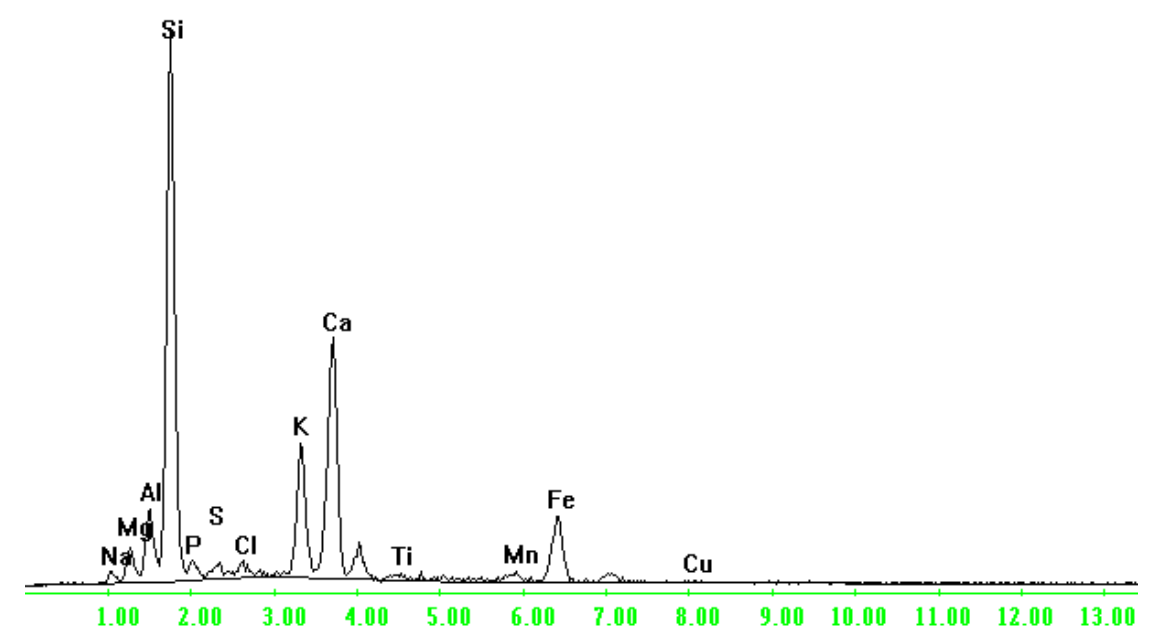

Figure 1. EDXA characterization of WCSA

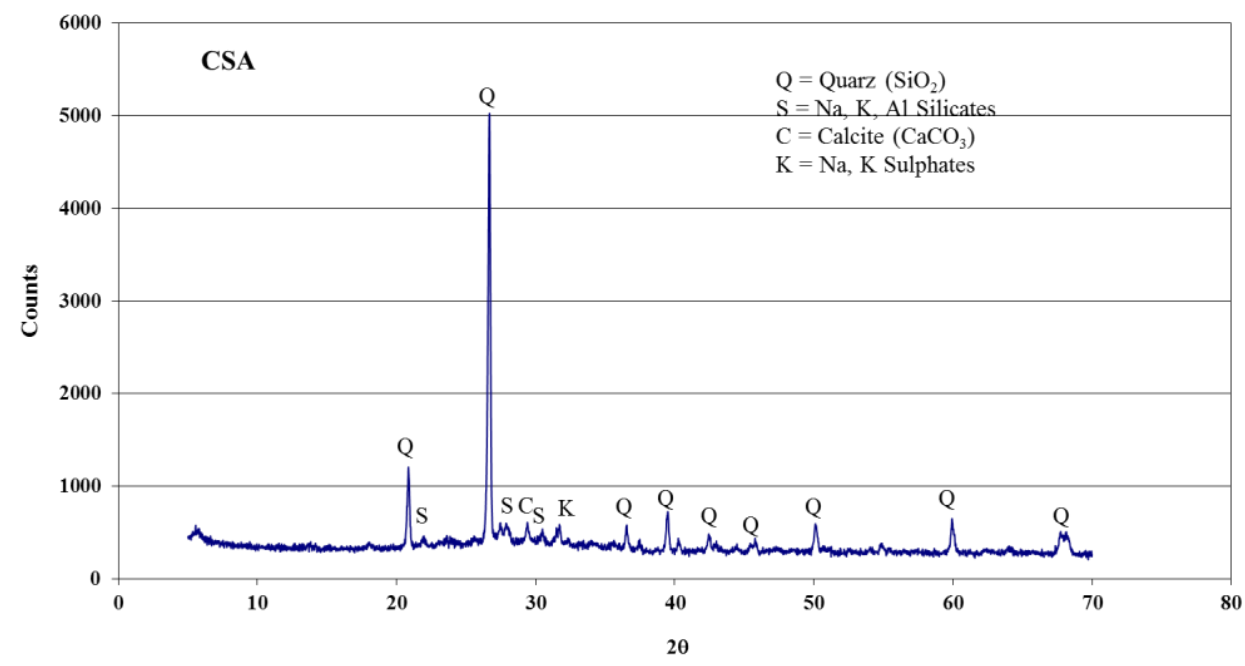

Figure 2. XRD pattern for WCSA 

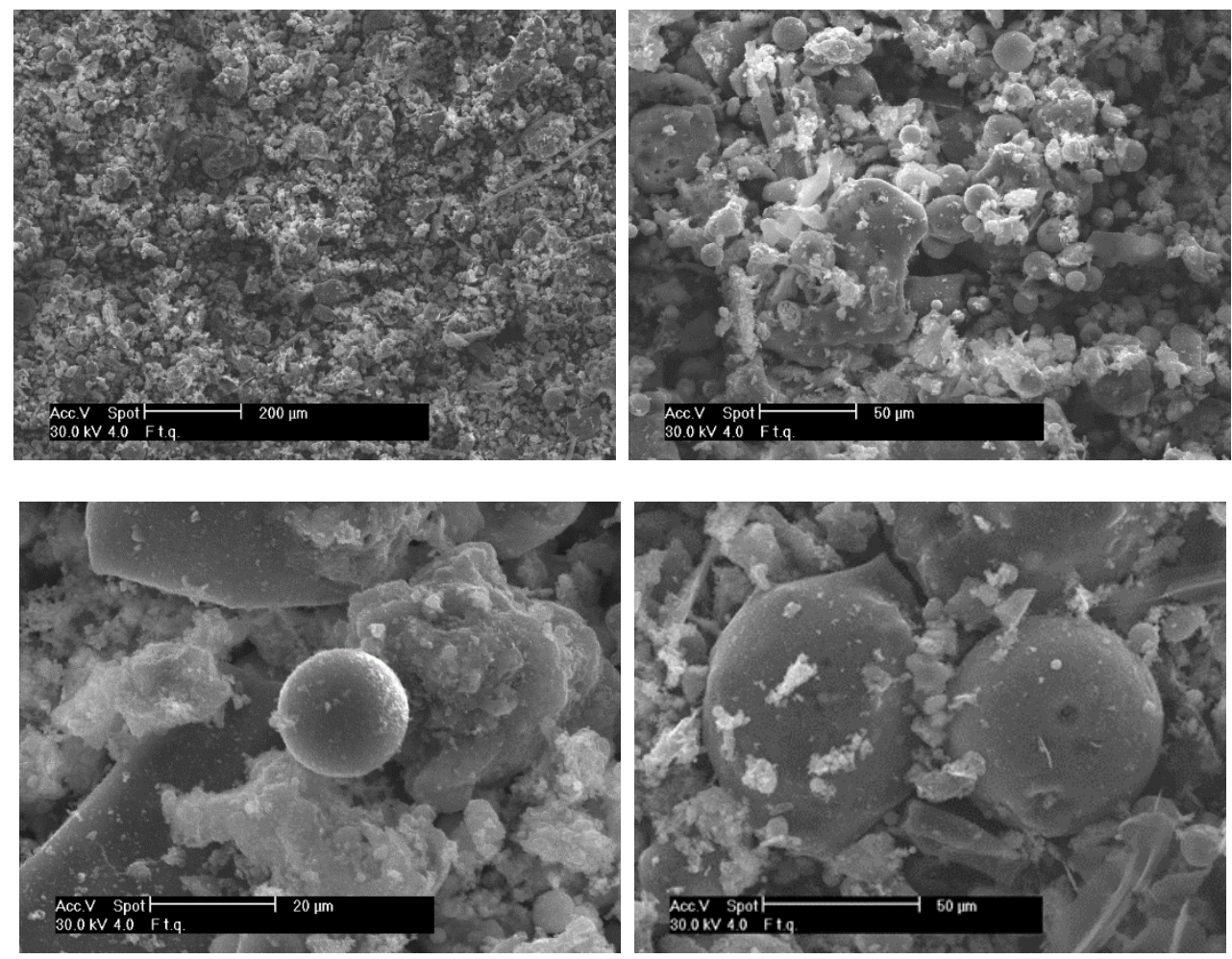

Figure 3, 4. Scanning electron micrograph of WCSA particles

\section{Specimens Preparation and Procedure}

Ordinary Portland Cement, CEM II/A-L 42.5R, and WCSA were used in preparing the mortar mixtures. The test specimens used in this study were 40 × 40 x $160 \mathrm{~mm}$ prismatic samples. The WCSA was added to the mortar mixture as a partial replacement of the cement at three levels: $10 \%, 20 \%$, and $30 \%$ by weight. A set of five specimen with water to cementitious materials ratio $(\mathrm{w} / \mathrm{cm})$ of 0.42 were prepared for each level of cement substitution; also another set of five specimen was prepared with a constant 0.5 water to cementitious ratio $(\mathrm{w} / \mathrm{cm})$. The workability of the mortar was WCSA measured according to UNI EN 1015-3 by the flow table test procedure for fresh mortars, by measuring the increase of the mortar diameter. For each mixture, the specimens were made and kept in the sealed steel prismatic moulds to allow hardening in the presence of relative humidity $(100 \%)$ and temperature $\left(26 \pm 2{ }^{\circ} \mathrm{C}\right)$, as constant as possible. They were removed from moulds at the age of $24 \mathrm{~h}$. After curing for 3, 7, 28, and 56 days they were demolded. An average of three specimens were used to measure the compressive strength at each test age. The leaching release was measured using the tank procedure following the Italian dynamic leaching test procedure (Legislative Decree, February, 5, 1998), at the age of 28. This procedure deals with Italian regulations for the reuse of non-toxic materials as by-products. Examples of similar international standard test include the ISO 6961:82, or the ASTM C 1220 [ASTM C1220:1992]. According to the extraction protocols, a specimen is placed in contact with a precise amount of deionized water for the predetermined extent of time. The solid to liquid ratio, expressed as the ratio of volume of solid to volume of the leachant, is 1:5. The volume of leaching solution is renewed for each specimen testing to drive the leaching process. At each renewing sequence, the fluid is collected for analysis. The renewing sequence was: $2,8,24,48,72,102,168$, and 384 hours. The leachant was freshly distilled water with $\mathrm{pH}$ of around 6.3 and electrical conductivity of around $3 \mu \mathrm{S} / \mathrm{cm}$, at room temperature of $20{ }^{\circ} \mathrm{C} \pm 4^{\circ} \mathrm{C}$. Because of the physical integrity of the sample matrix (which was maintained during the test), the specimen/leachant properties affect how much material can be leached out, as a function of time. In particular, the surface reactivity of the sample, more than the extraction force of the leachant, provides the concentrations of the contaminants in the water and the kinetic information about the dissolution process. 
Compressive strength. Prismatic samples having size $40 \mathrm{~mm}$ x $40 \mathrm{~mm}$ x $160 \mathrm{~mm}$ were cast in triplicates using WCSA as a partial replacement of cement. Mortar composition (in $\mathrm{kg} / \mathrm{m} 3$ ) for all the mixture proportions is presented in Table 3. After casting, all the test specimens were stored at a temperature of about $26 \pm 2{ }^{\circ} \mathrm{C}$ in the casting room. They were demolded after $24 \mathrm{~h}$, and were put to allow curing in the presence of relative humidity (100\%) for up to 90 days. Compressive strength of these concrete samples with WCSA was determined by the UNI EN 12390-3:2003 at the age of 3, 7, 28,56 days.

Micro-structural, chemical and physical ash characterization. Micro-structural analysis of the concrete was conducted using scanning electron microscope (SEM). Ash samples were dried for $24 \mathrm{~h}$ at $40{ }^{\circ} \mathrm{C}$. Then the samples were kept in desiccators for over-night for removal of moisture. The samples were coated with gold and analyzed by using Philips XL20 scanning electron microscope (SEM) at 30 $\mathrm{kV}$.

WCSAWCSA

Heavy metal leaching tests. The environmental impact of cement-based materials may be assessed through characterization of constituent release. Release characterization typically consist of monitoring the flux of constituent for potential concern from a saturated monolithic matrix. For environmental purposes, heavy metals are typically included as an important contaminant. However, cement durability assessment may necessitate focus on structural species and major ionic constituents $(\mathrm{Ca}, \mathrm{K}$, and $\mathrm{Na}$ ). Simulation of release may utilize models that describe the movement of dissolution fronts within saturated matrices using a diffusion-based released model [See http://www.cbu-uwm.info, 2015; ISO 6961:82]

\section{RESULTS AND DISCUSSION}

Measurements of the mortar workability, compressive strength, and leachate properties ( $\mathrm{pH}$, electrical conductivity, and Calcium ion release) were used for the evaluation of the effect of cement substitution with WCSA, as well as its suitability as a cementitious material. The mixture proportions WCSA and the effect on the workability are reported on Tables 3 and 4, while the compressive strength results are reported on Tables 5 and 6 . An attempt is made here to relate the compressive strength to maturity of mortars cured at $26{ }^{\circ} \mathrm{C}$. [Naik, 1980] Maturity is a product of time and temperature as expressed by $\mathrm{M}=\mathrm{T}(\mathrm{C}+10) . \mathrm{M}$ is the maturity in ${ }^{\circ} \mathrm{C} *$ hours, $\mathrm{T}$ is the curing time in hours; $\mathrm{C}$ is the mortars temperature in ${ }^{\circ} \mathrm{C}$. The constant 10 is a datum value which assumes that mortar continues to hydrate below the freezing point of water and down to a temperature of $-10^{\circ} \mathrm{C}$ (Neville 1995). The compressive strength $(\mathrm{MPa})$ and maturity $(\mathrm{M})$ of mortar can be related by the following equation 1 where a1 and b1 are constants.

$$
M P a=\frac{M}{a_{1} * M+b_{1}}
$$

The above equation was used to fit each data set of specimen tested using a least square method, allowing the constants $\mathrm{a}_{1}$ and $\mathrm{b}_{1}$ to be determined. The $\mathrm{R}^{2}$ for all sets is above 0.98 indicating an excellent correlation. It has been suggested that the inverse of constant $\mathrm{a}_{1}\left(1 / \mathrm{a}_{1}\right)$ is the limiting strength and the inverse of $b_{1}\left(1 / b_{1}\right)$ equals the initial slope of the strength-maturity relationship. Concrete gains strength gradually as a result of chemical reaction between cementitious material and water; and, for a specific concrete mixture, the strength at any age is related to the degree of hydration. Since the rate of hydration is a function of temperature, the strength development for a given cement-based material depends on its time-temperature history, assuming that sufficient moisture is available for hydration. This is the basis of the maturity concept, which was developed in the early 1950s to assess the development of in-situ concrete strength during construction. According to this concept, strength development of hardening cement-based materials, such as mortars and concrete, can be estimated at 
any age by computing the "maturity" based on the temperature and time history of the concrete [ASTM C1220:1992]. In the case of high-performance concrete, however, strength development could become more complex due to the combined physiochemical effects of pozzolans in concrete. The physical influence is in the refinement of pore structure of the cement paste, while the chemical phase consists of the pozzolanic reaction, which replaces $\mathrm{C}-\mathrm{H}$ crystals with cementitious C-S-H gel. However, partial replacement of cement in concrete by bio-mass-based pozzolans may produce an immediate dilution effect, depending upon the type and source of pozzolan [Dwivedi V. et al, 2006]. However, generally it is well established now that coal ash or rice-husk ash do not negatively affect early-age strength [See http://www.cbu-uwm.info; 2015]. In this paper, an investigation is reported that relate to the strength of concrete mixtures made with bio-mass pozzolans to the strength of the OPC, used as a control mixture. The parameters involved in this model are the pozzolanic and dilution factors, which depend on the amount of pozzolanic material present in the mixture. The key feature of this model is in its simplicity; since other factors relating to water-cementitious materials ratio $(w / \mathrm{cm})$, age, cement content and temperature can be disregarded because both the pozzolanic and control mixtures have similar material proportions and are assumed to have undergone the same curing history.

Table 3. Mixture proportions of mortars

\begin{tabular}{|c|c|c|c|c|c|}
\hline $\begin{array}{c}\text { WCSA } \\
\%\end{array}$ & $\begin{array}{c}\text { Water } \\
(\mathrm{ml})\end{array}$ & $\begin{array}{c}\text { CEM } \\
\text { II/A-L } \\
32,5 \mathrm{R}\end{array}$ & $\begin{array}{c}\text { Ash } \\
(\mathrm{g})\end{array}$ & $\begin{array}{c}\text { Sand } \\
(\mathrm{g})\end{array}$ & w/cm \\
\hline 0 & 189 & 450 & 0 & 1350 & 0,42 \\
\hline $10 \%$ & 193 & 405 & 54 & 1350 & 0,42 \\
\hline $20 \%$ & 197 & 360 & 108 & 1350 & 0.42 \\
\hline $30 \%$ & 200 & 315 & 152 & 1350 & 0,42 \\
\hline
\end{tabular}

\begin{tabular}{|c|c|c|c|c|c|}
\hline $\begin{array}{c}\text { WCSA } \\
\%\end{array}$ & $\begin{array}{c}\text { Water } \\
(\mathrm{ml})\end{array}$ & $\begin{array}{c}\text { CEM } \\
\text { II/A-L } \\
32,5 \mathrm{R}\end{array}$ & $\begin{array}{c}\text { Ash } \\
(\mathrm{g})\end{array}$ & $\begin{array}{c}\text { Sand } \\
(\mathrm{g})\end{array}$ & w/cm \\
\hline 0 & 227 & 450 & 0 & 1426 & 0,5 \\
\hline $10 \%$ & 244 & 405 & 45,2 & 1426 & 0,5 \\
\hline $20 \%$ & 262 & 360 & 90,4 & 1426 & 0,5 \\
\hline $30 \%$ & 280 & 315 & 135,5 & 1426 & 0,5 \\
\hline
\end{tabular}

Table 4. Workability of mixture

\begin{tabular}{|c|c|c|c|c|}
\hline $\begin{array}{c}\text { WCSA } \\
\%\end{array}$ & w/cm & Average diameter $(\mathrm{cm})$ & w/cm & $\begin{array}{c}\text { Average } \\
\text { diameter }(\mathrm{cm})\end{array}$ \\
\hline 0 & 0.42 & 13 & 0.5 & 14 \\
\hline 10 & 0.42 & 13 & 0.5 & 16 \\
\hline 20 & 0.42 & 13 & 0.5 & 18 \\
\hline 30 & 0.42 & 13 & 0.5 & 19 \\
\hline
\end{tabular}

Table 5. Compressive strength development (MPa)

$w / \mathrm{cm}=0.42$

\begin{tabular}{|l|l|l|l|l|}
\hline $\begin{array}{l}\text { Age, } \\
\text { days }\end{array}$ & Control & $10 \%$ & $20 \%$ & $30 \%$ \\
\hline 3 & 28.0 & 26.4 & 26.6 & 23.3 \\
\hline 7 & 32.5 & 35.0 & 32.3 & 25.6 \\
\hline 28 & 38.4 & 38.8 & 36.7 & 37.2 \\
\hline 56 & 38.7 & 40.0 & 37.2 & 37.3 \\
\hline
\end{tabular}

$w / \mathrm{cm}=0.5$

\begin{tabular}{|l|l|l|l|l|}
\hline $\begin{array}{l}\text { Age, } \\
\text { days }\end{array}$ & Control & $10 \%$ & $20 \%$ & $30 \%$ \\
\hline 3 & 22.0 & 17.8 & 14.6 & 14.9 \\
\hline 7 & 27.4 & 21.3 & 17.6 & 19.4 \\
\hline 28 & 30.6 & 27.9 & 25.2 & 26.7 \\
\hline 56 & 31.4 & 28.2 & 25.7 & 27.6 \\
\hline
\end{tabular}

Table 6. Equation 1 parameters 
$w / c m=0.42$

\begin{tabular}{|c|c|c|}
\hline $\begin{array}{c}\text { Sample } \\
\text { ash\% }\end{array}$ & $\begin{array}{c}1 / \mathrm{b} 1 \\
(-)\end{array}$ & $\begin{array}{c}1 / \mathrm{a} 1 \\
(\mathrm{MPa})\end{array}$ \\
\hline 0 & 0.047 & 39.1 \\
\hline 10 & 0.036 & 41.4 \\
\hline 20 & 0.036 & 40.3 \\
\hline 30 & 0.022 & 38.6 \\
\hline
\end{tabular}

$w / c m=0.5$

\begin{tabular}{|c|c|c|}
\hline $\begin{array}{c}\text { Sample } \\
\text { ash\% }\end{array}$ & $\begin{array}{c}1 / \mathrm{b} 1 \\
(-)\end{array}$ & $\begin{array}{c}1 / \mathrm{a} 1 \\
(\mathrm{MPa})\end{array}$ \\
\hline 0 & 0.031 & 31.9 \\
\hline 10 & 0.022 & 27.4 \\
\hline 20 & 0.014 & 25.1 \\
\hline 30 & 0.013 & 28.6 \\
\hline
\end{tabular}

The results show that for the $w / \mathrm{cm}$ ratio, when fixed at 0.42 and the WCSA to cement substitution up to $20 \%$ in the mixture, does not reduce the compressive strength. Conversely fixing a higher $\mathrm{w} / \mathrm{cm}$ ratio at 0.50 , a progressive reduction becomes more evident. However the substitution effect becomes explicit following the 1/b1 parameter, the initial slope of the maturity-strength. The sharp decrease observed for both the set of data suggest a possible marked effect during the early stages of hydration. In the long-term the compressive strength for the lower w/cm ratio (0.42) increases, while for the higher $0.5 \mathrm{w} / \mathrm{cm}$ ratio the compressive strength slope down. Briefly, the full set of results obtained may be attributed, beside the partial cement substitution with WCSA, to the water to cementitious material adopted, along with the pozzolanic effect of the WCSA used.

Heavy metal leaching tests. The environmental impact of cement-based materials may be assessed through characterisation of constituent release. Release characterisation typically consists of monitoring the flux of the constituent of the potential concern from a saturated monolithic matrix. For environmental purposes, heavy metals are typically included as an important contaminant; however, cement durability assessment may also necessitates a focus on structural species and major ionic constituents $(\mathrm{Ca}, \mathrm{K}, \mathrm{Na})$. Simulation of releases usually utilizes models that describe the movement of dissolution fronts within saturated matrices using a diffusion-based release model [See, http://www.cbu-uwm.info 2015; ASTMC1220:1992]. The obtained heavy metal leachate concentrations fully conform to the Italian legal standards. As shown in Table 7, concrete specimens manufactured with or without WCSA showed comparable releases. All leachates, alkaline throughout the testing period with $\mathrm{pH}$ values greater than 10 , indicate that the interstitial pore fluid in contact with hydrated cementitious materials is buffered by the presence of portlandite and alkaline ions. So far, as the local condition of the leachant remain unchanged, the heavy metals leaching remains very low, as found in a previous publication [Naik 1980].

Table 7. Cumulated heavy metals (mg/l) in the leaching solution.

\begin{tabular}{|c|c|c|c|c|c|c|c|}
\hline$\%$ WCSA & $\mathrm{Ba}$ & $\mathrm{Cr}$ & $\mathrm{Cu}$ & $\mathrm{Ni}$ & $\mathrm{Pb}$ & $\mathrm{V}$ & $\mathrm{Zn}$ \\
\hline 0 & 0.087 & 0.008 & 0.042 & 0.004 & 0.003 & 0.008 & 0.128 \\
\hline 10 & 0.082 & 0.007 & 0.008 & 0.002 & 0.002 & 0.011 & 0.113 \\
\hline 20 & 0.049 & 0.005 & 0.009 & 0.005 & 0.001 & 0.007 & 0.386 \\
\hline 30 & 0.285 & 0.006 & 0.013 & 0.004 & 0.001 & 0.015 & 0.001 \\
\hline 0 & 0.272 & 0.008 & 0.019 & 0.003 & 0.002 & 0.012 & 0.001 \\
\hline 10 & 0.079 & 0.026 & 0.037 & 0.007 & 0.005 & 0.026 & 0.116 \\
\hline 20 & 0.034 & 0.011 & 0.015 & 0.006 & 0.002 & 0.026 & 0.001 \\
\hline 30 & 0.143 & 0.008 & 0.011 & 0.008 & 0.003 & 0.010 & 0.298 \\
\hline ref. limit & 1.0 & 0.05 & $0.05 l$ & 0.01 & 0.05 & 0.25 & 3.0 \\
\hline
\end{tabular}

$A s, B e, C d$, Co, concentration under detection limit. 
The alkaline cations release involves mainly the $\mathrm{Ca}^{2+}$ and $\mathrm{K}^{+}$, which are the elements that are found in higher concentrations in the pore water analysis. This was somewhat expected since, among other things, the major product of OPC hydration include portlandite $\left(\mathrm{Ca}(\mathrm{OH})_{2}\right)$. Calcium ions are also abundant in the WCSA and $\mathrm{K}^{+}$is the major alkaline constituent of the ash residue. Adopting the maturity approach, as the hydration model related to the release of the Calcium ions and diffused within the pore water, one can obtain from the Equation 1 the parameters (a1, b1) describing the ionic development. In Table 8, the calcium release is expressed as milli-equivalent (meq) of calcium ions for each specimen.

Table 8. Equation 1 parameters

\begin{tabular}{|l|l|l||l|l|l|}
\hline $\begin{array}{l}(\mathrm{w} / \mathrm{cm}=0.42) \\
\text { ash\% }\end{array}$ & $\begin{array}{l}1 / \mathrm{b} 1 \\
-\end{array}$ & $\begin{array}{l}1 / \mathrm{a} 1 \\
(\mathrm{meq} C a)\end{array}$ & $\begin{array}{l}(\mathrm{w} / \mathrm{cm}=0.5) \\
\text { ash\% }\end{array}$ & $\begin{array}{l}1 / \mathrm{b} 1 \\
-\end{array}$ & $\begin{array}{l}1 / \mathrm{a} 1 \\
(\mathrm{meq} \mathrm{Ca})\end{array}$ \\
\hline 0 & 0.094 & 10.58 & 0 & 0.049 & 20.31 \\
\hline 10 & 0.073 & 13.61 & 10 & 0.062 & 16.04 \\
\hline 20 & 0.124 & 8.06 & 20 & 0.075 & 13.23 \\
\hline 30 & 0.183 & 5.45 & 30 & 0.074 & 13.41 \\
\hline
\end{tabular}

The leaching history manifested by each specimen within the two set of w/cm ratio $(0.42$ and 0.50$)$ comply with the corresponding strength development as showed in Figs. 5 and 6

Figure 5. Strength (MP) Vs WCSA \%

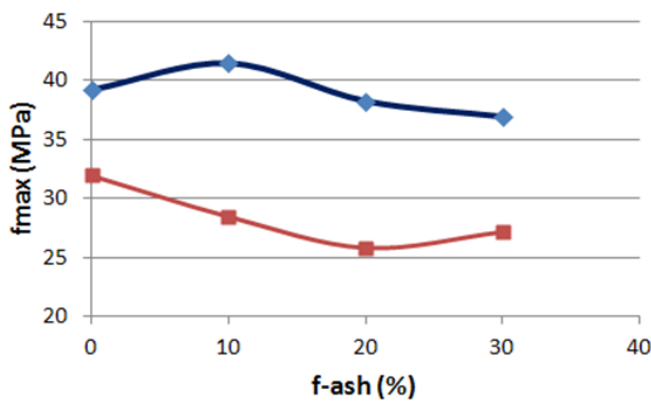

Figure 6. mEq Calcium release Vs WCSA \%

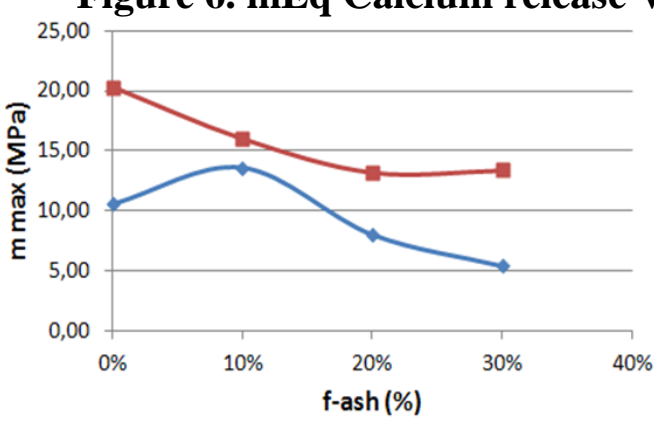

The peculiar symmetry observed enables to find a relationship between the specimen characteristics through a multiple regression analysis, taking the mass of calcium ions leached as independent variable and the mixture composition with the compressive strength (MPa) as dependent variables. The results can be summarized in the Equation 2 and in Figure 7.

$m E q_{C a}=\frac{M P a}{0.739}-0.5 \times g_{\text {water }}+0.93 \times g_{\text {cem }}+0.73 \times g_{C S A}-552$

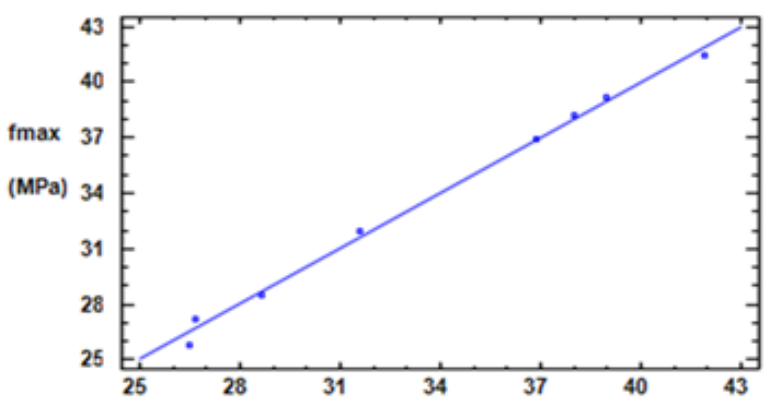

Figure 7. Observed versus predicted values adopting Equation 


\section{CONCLUSION}

The wood, corn stover \& cob Ash (WCSA) examined in this study is characterized by high amounts of Silicium (39\%), calcium (16\%), and potassium ions (7\%) not different from many other biomass ash composition found in the literature [Stanislav V. et al 2013]. For the constant $\mathrm{w} / \mathrm{cm}$ ratio of 0.42 , the compressive strength of prismatic mortars specimens, obtained with WCSA up to $20 \%$ as a partial replacement of cement, show a small increase, without losing workability. However, at higher w/cm a clear performance decrease has been observed. The chemical properties of the pore solution given by the leaching tests are characterized by high concentration of Calcium and Potassium ions. Particularly the Calcium ion leached by WCSA specimens, with respect to the control mixture specimens, indicates a notable alteration of the pore water chemistry. This change has been attributed either to the particular composition of the WCSA examined or to the cement hydration delay as indicated by the kinetics values obtained from the diffusion model adopted.

In conclusion, it is believed that with additional studies, regarding the use of WCSA, can be put to good use; and, therefore WCSA can be diverted from landfill.

\section{REFERENCES}

ASTM C1220:1992, "Static Leaching of Monolithic Waste Forms for Disposal of Radioactive Wastes". American Society for Testing and Materials, Annual Book of ASTM Standards, 04.02. West Conshohocken, Pennsylvania.

Bakisgan C., Gümrah Dumanli. A., Yürüm Y. (2009). "Trace elements in Turkish biomass fuels: Ashes of wheat straw, olive bagasse and hazelnut shell" Fuel 88 1842-1851

Berra M., De Casa G., Ergul S., Mangialardi T., Paolini A.E.,(2009) "Use of co-fired woody biomass and peat fly ash in cementitious mixes", VII International Congress Valorisation and Recycling of Industrial WCSAstes, VARIREI 2009, L'Aquila, 21-23 Settembre 2009.

Dwivedi V, Singh N, Das S and Singh N. (2006) "A new pozzolanic material for cement industry: Bamboo leaf ash” International Journal of Physical Sciences, 3 106-111.

Elinwa, A.U Mahmood ,Y.A. (2002). "Ash from timber waste as cement replacement material." Cem. Concr. Compos. 24(2),219-222.

Italian Decree "Decreto Legislativo 5 Febbraio 1997" Artt. 31,33

Kaltschmitt M., Lenz V, Thrän D. (2008) "Zur energetischen Nutzung von Biomasse in Deutschland Potenziale, Stand und Perspektiven”. LIFIS ONLINE [25.04.08] www.leibniz-institut.de ISSN 18646972.

Kosson, D.S.van der Sloot, H.H. Eighmy T.T.(1996) “An Approach for estimating of contaminants release during utilization and disposal of municipal waste combustion residues" 1996 Journal of Hazardous Materials 47, 43-75.

Maciejewska, A. Veringa H,. Sanders .J., Peteves, S. D. (2006) "Co-firing of biomass with coal: constraints and role of biomass pre-treatment", EUR 22461, European Commission, Directorate General, Joint Research Center, WCSAgeningen.

Naik T.R., Singh S.S., Ramme B.W. 2001 Performance and Leaching Assessment of Flowable Slurry, Journal of Environmental Engineering, 127(4).

Naik, T. R. (1980) "In-Place Concrete Strength Determination by the Maturity Method" ASCE Journal of the Engineering Mechanics Divison, June, pp. 465-480.

Naik, T. R. and Kraus, R. N., (2003) "A New Source of Pozzolanic Materials," ACI Concrete International, Vol. 25, No. 12, ACI, Dec. 2003, pp. 55-62."

Sani D., Moriconi G., Fava G., Corinaldesi V. 2003. "Leaching and mechanical behaviour of concretes manufactured with recycled aggregates". Waste Management, Elsevier Science Ltd.

See Internet site for publications related to biomass ash use: http://www.cbu-uwm.info/; accessed July 11, 2015.

Stanislav V. Vassilev a,b, $\Uparrow$, David Baxter a, Lars K. Andersen a, Christina G. Vassileva (2013). An overview of the composition and application of biomass ash. Part 1. "Phase-mineral and chemical composition and classification" 2013 Fuel 105, 4076. 
Thrän, D. "Sustainable Strategies for Biomass Use in the European Context. Analysis in the charged debate 011 national guidelines and the competition between solid, liquid and gaseous biofuels". IE-Report 1 2006. Leipzig 2006 